\title{
Pharmacokinetics and pharmacodynamics of levofloxacin in bronchial mucosa and lung tissue of patients undergoing pulmonary operation
}

\author{
GUOYING CAO ${ }^{1-4}$, YONGJUN ZHU ${ }^{4,5}$, XIN XIE $^{1,2,4}$, YUANCHENG CHEN $^{1-4}$, JICHENG YU $^{1-4}$, \\ JING ZHANG ${ }^{1,2,4}$, ZHIMING $\mathrm{CHEN}^{4,5}$, LIEWEN PANG ${ }^{4,5}$, YINGYUAN ZHANG ${ }^{1,2,4}$ and YAOGUO SHI ${ }^{1,2,4}$ \\ ${ }^{1}$ Institute of Antibiotics, Huashan Hospital, Fudan University; ${ }^{2}$ Key Laboratory of Clinical Pharmacology of Antibiotics, \\ National Health Commission; ${ }^{3}$ Phase I Unit, Huashan Hospital, Fudan University; ${ }^{4}$ National Clinical Research \\ Center for Aging and Medicine, Huashan Hospital, Fudan University; ${ }^{5}$ Department of Thoracic Surgery, \\ Huashan Hospital, Fudan University, Shanghai 200040, P.R. China
}

Received April 11, 2019; Accepted March 10, 2020

DOI: $10.3892 /$ etm. 2020.8715

\begin{abstract}
Levofloxacin is a major antimicrobial agent that is used for the treatment of community-acquired lower respiratory tract infections (LRTIs). The present study was designed to investigate the pharmacokinetics (PK) and pharmacodynamics (PD) of levofloxacin in bronchial mucosa and lung tissue. A total of 32 patients undergoing pulmonary surgery were randomly assigned to one of four groups ( 8 subjects/group). All patients received a single dose of $500 \mathrm{mg}$ levofloxacin orally prior to the operation. Blood, lung tissue and bronchial mucosa samples were collected prior to treatment and at 1.5, 4, 8, 12 and $24 \mathrm{~h}$ following treatment. The drug concentration was determined and PK and PD profiles were calculated using MATLAB software. The peak concentration of levofloxacin was $7.0 \pm 1.2 \mu \mathrm{g} / \mathrm{g}$ in lung tissues and 9.4 $\pm 2.1 \mu \mathrm{g} / \mathrm{g}$ in bronchial mucosa. The corresponding area under the curve between 0 and $24 \mathrm{~h}\left(\mathrm{AUC}_{0-24}\right)$ was $85.7 \pm 8.5$ and $137.3 \pm 19.4 \mu \mathrm{g} \mathrm{h} / \mathrm{g}$. The mean permeability of levofloxacin (ratio of concentration in tissue to that in plasma) was 2.4 in lung tissue and 4.4 in the bronchial mucosa. The PK profiles of levofloxacin in the plasma, lung and bronchial mucosa were described using an integrated one-compartment model. The probability of $f \mathrm{AUC}_{0-24} / \mathrm{minimal}$ inhibitory concentration (MIC) target attainment of levofloxacin against
\end{abstract}

Correspondence to: Professor Jing Zhang, Institute of Antibiotics, Huashan Hospital, Fudan University, 12 Middle Wulumuqi Road, Shanghai 200040, P.R. China

E-mail: zhangj_fudan@aliyun.com

Dr Zhiming Chen, Department of Thoracic Surgery, Huashan Hospital, Fudan University, 12 Middle Wulumuqi Road, Shanghai 200040, P.R.China

E-mail: chzm_md@163.com

Key words: levofloxacin, bronchial mucosa, lung tissue, pharmacokinetics, pharmacodynamics, pulmonary operation
Streptococcus pneumoniae in the lung and bronchial mucosa was maintained at $100 \%$ when $\mathrm{MIC} \leq 1 \mathrm{mg} / \mathrm{l}$, while the cumulative fraction of $f \mathrm{AUC}_{0-24} / \mathrm{MIC}$ in the corresponding tissues was 94.4 and $98.1 \%$, respectively. The present study demonstrated the high permeability of levofloxacin in the lung and bronchial mucosa of patients undergoing pulmonary surgery. In conclusion, treatment using $500 \mathrm{mg}$ levofloxacin exhibits good clinical and microbiological efficacy for use in LRTIs that are caused by $S$. pneumoniae. This trial was registered retrospectively in the Chinese Clinical Trial Registry on January 13, 2020 (registration no. ChiCTR2000029096).

\section{Introduction}

Levofloxacin is a third-generation fluoroquinolone antibiotic with wide-spectrum and potent in vitro antimicrobial activity against aerobic gram-negative and -positive microorganisms (1). Levofloxacin exhibits favorable pharmacokinetic (PK) and pharmacodynamic (PD) features, including high bactericidal activity, good absorption, high blood concentration, wide distribution, high tissue permeability and bioavailability (2-4). Levofloxacin is one of the major antimicrobial agents for the treatment of community-acquired lower respiratory tract infections (LRTIs) (5). The PK/PD parameters of levofloxacin, including the peak serum concentration $\left(\mathrm{C}_{\max }\right)$ /minimum inhibitory concentration (MIC) and area under the concentration-time curve from time 0 to $24 \mathrm{~h}$ $\left(\mathrm{AUC}_{0-24 \mathrm{~h}}\right) / \mathrm{MIC}$, are closely associated with the clinical efficacy, bacterial eradication and prevention of the emergence of resistant bacteria in infectious diseases (6). Levofloxacin is used in clinical practice worldwide, particularly for the treatment of community-acquired pneumonia and acute exacerbation of chronic bronchitis (7-10).

Pulmonary operation is a clean-contaminated surgery (Altemeier Class II) and this procedure is likely to include contamination of bacteria colonizing the tracheal or bronchial mucosa, which is one of the major risk factors for peri-operative infection (11). Antimicrobial agents with good pathogen coverage and tissue penetration should be considered to 
prevent post-operative infections in clinical practice (12-20). Therefore, it is beneficial to perform studies in patients undergoing pulmonary operation who require antimicrobial agents to prevent potential infections due to external bacterial infection from an open airway and/or the colonizing microorganisms in the respiratory tract.

The present study was designed to examine the PK profiles and PK/PD of levofloxacin in bronchial mucosa and lung tissue. Patients undergoing pulmonary operation and those who required prophylactic antimicrobial therapy were included. All patients received levofloxacin prophylactically prior to the operation. The concentration of levofloxacin in the bronchial mucosa and lung tissues was determined and PK/PD analysis was performed using Monte Carlo simulation. The results provided information regarding the levofloxacin concentration in pulmonary tissues. An optimized dosing regimen allowing for the maximal bactericidal effect to be achieved in vivo was also recommended for patients with pulmonary disease.

\section{Materials and methods}

Study design. The present study was a randomized, single-center, open-label clinical trial. The protocol was reviewed and approved by the Ethics Committee of Huashan Hospital, Fudan University (Shanghai, China; approval no. 66; 2006). All patients signed an informed consent form prior to participation in the present study. The study was performed in compliance with the ethical principles outlined in the Declaration of Helsinki and all applicable regulatory requirements. The procedure of the present study is outlined in Table I. Since the study was designed as a pharmacokinetic study to explore the penetration of levofloxacin in tissue, it was not a comparative or controlled study. According to the Guidance for Industry on Population Pharmacokinetics released by the US Food and Drug Administration in July 2019, the data indicating the outcome of patients and the incidence of post-operative infections were not collected. The aim of the present study was to investigate the PK of a single drug, and therefore, no other drug was used for comparison.

Participants. Recruitment of participants was performed in Shanghai. Patients who received a pulmonary operation at Huashan Hospital (Shanghai, China) due to pulmonary disease from June 2006 to June 2007 were enrolled according to the following inclusion criteria: i) age, at least 18 years; ii) requirement of pulmonary operation; and iii) voluntary agreement to participate and signing of informed consent form prior to the study procedure. Patients were excluded if they had severe pneumonia, moderate or severe renal impairment, or clinically significant abnormal liver function, which was defined as alanine aminotransferase or/and aspartate aminotransferase $>3$-fold the upper limit of the normal range (ULN) or total bilirubin $>2$-fold ULN. Creatinine clearance $\left(\mathrm{CL}_{\mathrm{cr}}\right)$ was calculated according to the Cockcroft-Gault formula (21):

$$
\mathrm{CL}_{\mathrm{cr}}(\mathrm{ml} / \mathrm{min})=\frac{[140-\text { age }(\text { years })] \times B W(\mathrm{~kg})}{0.818 \times \operatorname{Scr}(\mu \mathrm{mol} / \mathrm{l})} \times 0.85(\text { if female })
$$

Where BW is the body weight and Scr indicates serum creatinine. Patients were excluded if they had a history of hypersensitivity to fluoroquinolones or other drugs, or photosensitivity, a history of epilepsy or other disorders of the central nervous system, documented QT prolongation or severe cardiac insufficiency. Pregnant or lactating females and patients that were treated with levofloxacin or other fluoroquinolones within 2 weeks prior to screening were also excluded from the present study.

Study drug. Levofloxacin $500 \mathrm{mg}$ tablets (lot no. 0506G03) were provided by Daiichi Sankyo Co., Ltd.

Sample collection. The eligible patients were assigned randomly to one of four groups (8 subjects/group) according to the time of sampling. All patients received a single dose of $500 \mathrm{mg}$ levofloxacin orally prior to pulmonary operation. Blood samples were collected prior to treatment, and at $1.5,4,8,12$ or $24 \mathrm{~h}$ following treatment. The samples of lung tissue and bronchial mucosa were collected at $4,8,12$ or $24 \mathrm{~h}$ following treatment. Detailed sampling time points for the collection of blood or tissue samples are presented in Table II. The present study did not have a negative control, as the aim of the study was to observe PK of levofloxacin in the tissue and blood of patients.

All enrolled patients received a pulmonary operation due to lung cancer $(n=23)$ or other pulmonary diseases, including old tuberculoma $(n=3)$, pulmonary granuloma $(n=3)$, right lung angioma, chronic cavity in right lower lobe, and bronchiectasis in left lung (one each). The patients with peripheral lung cancer received a lobectomy, and the patients with central type lung cancer were sampled using a unilateral pneumonectomy. A sample of lung tissue $\sim 1 \mathrm{~cm}^{2}$ was collected from the external side of the excised lung lobe and rinsed twice with normal saline. The moisture on the surface was dried using a clean gauze. Bronchial rings were excised from the residual end of lung cancer specimen in patients with peripheral lung cancer, while adequate bronchial mucosa was collected from the patients with central type lung cancer to avoid tumor tissue. The bronchial mucosa samples were rinsed using the same procedures used for lung tissue samples. The samples of lung tissue and bronchial mucosa were sectioned into pieces, and a fixed volume of $50 \mathrm{mmol} / 1 \mathrm{KH}_{2} \mathrm{PO}_{4}$ buffer was added. Homogenate was extracted using an ultrasonic homogenizer, and tissues were centrifuged to harvest the supernatant. Blood samples were heparinized and centrifuged at $4^{\circ} \mathrm{C}, 1,500 \mathrm{x} \mathrm{g}$ for $10 \mathrm{~min}$ to separate plasma. All samples were stored in a refrigerator at $-40^{\circ} \mathrm{C}$ and in dark conditions until subsequent analysis.

Levofloxacin assay and method validation. High-performance liquid chromatography was used to determine the concentration of levofloxacin in blood and tissue samples. The method used has been reported in a previous study (22). The analytical system consisted of a high-performance liquid chromatographer Waters model 2690 equipped with a fluorescent detector (model 474; Waters Corp.), which measured at wavelengths of $296 \mathrm{~mm}$ (excitation) and $504 \mathrm{~nm}$ (emission). The stationary phase was a TSK-gel ODS-80 ${ }^{\mathrm{TM}} \mathrm{C}_{18}$ column $(4.6 \times 150 \mathrm{~mm}$; $5 \mu \mathrm{m}$; Tosoh Corporation). The mobile phase consisted of $50 \mathrm{mmol} / 1 \mathrm{KH}_{2} \mathrm{PO}_{4}(\mathrm{pH}$ 2.0)-tetrahydrofuran-1 mol/1 acetonitrile $(92 / 7 / 1 ; \mathrm{v} / \mathrm{v} / \mathrm{v})$. The analysis was performed at a flow rate of $1.0 \mathrm{ml} / \mathrm{min}$, a column temperature of $35^{\circ} \mathrm{C}$ and an injection 
Table I. Flowchart of the study.

\begin{tabular}{|c|c|c|c|c|c|c|}
\hline \multirow[b]{2}{*}{ Procedure } & \multirow{2}{*}{$\frac{\text { Screening }}{\mathrm{D}-28 \text { to D-2 }}$} & \multicolumn{5}{|c|}{ Experiment } \\
\hline & & D-1 & D1 & $\mathrm{D} 2$ & D3 & D4 \\
\hline Informed consent & $X$ & & & & & \\
\hline Medical history & $X$ & $\mathrm{X}$ & & & & \\
\hline Physical examination & $\mathrm{X}$ & $\mathrm{X}$ & & & & $\mathrm{X}$ \\
\hline Vital sign & $\mathrm{X}$ & $\mathrm{X}$ & $\mathrm{X}$ & & & $\mathrm{X}$ \\
\hline Chest X-ray & $\mathrm{X}$ & & & & & \\
\hline 12-lead ECG & $\mathrm{X}$ & $\mathrm{X}$ & & & & $\mathrm{X}$ \\
\hline Body weight & $X$ & $\mathrm{X}$ & & & & $\mathrm{X}$ \\
\hline Inclusion/exclusion criteria & $X$ & $\mathrm{X}$ & & & & \\
\hline \multicolumn{7}{|l|}{ Laboratory tests } \\
\hline Immunology & $X$ & & & & & \\
\hline Hematology, biochemistry, urinalysis & $X$ & $\mathrm{X}$ & & & & $\mathrm{X}$ \\
\hline Endogenous creatinine clearance rate & $\mathrm{X}$ & $\mathrm{X}$ & & & & $\mathrm{X}$ \\
\hline Stay in hospital & & $\mathrm{X}$ & $\mathrm{X}$ & $\mathrm{X}$ & $\mathrm{X}$ & $\mathrm{X}$ \\
\hline Drug administration & & & $\mathrm{X}$ & & & \\
\hline Clinical observation & $\mathrm{X}$ & $\mathrm{X}$ & $\mathrm{X}$ & $\mathrm{X}$ & $\mathrm{X}$ & $\mathrm{X}$ \\
\hline \multicolumn{7}{|l|}{ Pharmacokinetic evaluation } \\
\hline Blood sampling & & & $\mathrm{X}$ & $\mathrm{X}$ & & \\
\hline Tissue sampling & & & $\mathrm{X}$ & $\mathrm{X}$ & & \\
\hline
\end{tabular}

$\mathrm{X}$ means the procedure will be performed. ECG, electrocardiogram; D1, first day of the major experiment.

Table II. Time-points for collecting blood or tissue samples from patients undergoing pulmonary operation.

\begin{tabular}{lclc}
\hline & & \multicolumn{2}{c}{ Sampling time-point } \\
\cline { 3 - 4 } Group & Number of subjects & \multicolumn{1}{c}{ Blood } & Lung tissue and bronchial mucosa \\
\hline 1 & 8 & Pre-dose, $1.5 \mathrm{~h} ; 4 \mathrm{~h}$ post-dose & 4 h post-dose \\
2 & 8 & Pre-dose, $1.5 \mathrm{~h} ; 8 \mathrm{~h}$ post-dose & 8 h post-dose \\
3 & 8 & Pre-dose, $1.5 \mathrm{~h} ; 12 \mathrm{~h}$ post-dose & $12 \mathrm{~h}$ post-dose \\
4 & 8 & Pre-dose, $1.5 \mathrm{~h} ; 24 \mathrm{~h}$ post-dose & $24 \mathrm{~h}$ post-dose \\
\hline
\end{tabular}

volume of $10 \mu \mathrm{l}$. Compound DL-8493 was used as an internal control, which was provided by Daiichi Sankyo Co., Ltd. The lower limit of quantitation was $0.0100 \mu \mathrm{g} / \mathrm{ml}$ and the linear range was $0.01-5 \mu \mathrm{g} / \mathrm{ml}$. The recovery of levofloxacin was $99.6 \pm 1.6 \%, 101.3 \pm 2.2 \%$ and $100.8 \pm 1.3 \%$ from plasma, lung tissue and bronchial mucosa, respectively. For the plasma and buffer samples, the intra-day relative standard deviation was $\leq 4.1$ and $\leq 1.8 \%$, while the inter-day variability was $\leq 2.5$ and $\leq 4.2 \%$, respectively. The corresponding accuracy was $96.1-101.9 \%$ and $96.2-103.1 \%$.

$P K$ evaluation. The PK parameters of levofloxacin in plasma, lung and bronchial mucosa were obtained using non-compartment analysis. The parameters included $\mathrm{C}_{\max }$, peak time $\left(\mathrm{T}_{\max }\right)$, $\mathrm{AUC}_{0-24}$, area under the time-concentration curve from time zero to infinity $\left(\mathrm{AUC}_{0-\infty}\right)$, half life $\left(\mathrm{T}_{1 / 2}\right)$, mean residence time until $24 \mathrm{~h}\left(\mathrm{MRT}_{0-24}\right)$, total apparent clearance $\left(\mathrm{CL}_{\mathrm{t}} / \mathrm{F}\right)$, apparent volume of distribution $\left(\mathrm{V}_{\mathrm{d}} / \mathrm{F}\right)$, the ratio of $\mathrm{C}_{\max }$ in tissue vs. plasma $\left(\mathrm{R}_{\mathrm{Cmax}}\right)$, the ratio of levofloxacin $\mathrm{AUC}_{0-24}$ in tissue vs. plasma $\left(\mathrm{R}_{\mathrm{AUC} \_0-24}\right)$ and the ratio of levofloxacin $\mathrm{AUC}_{0-\infty}$ in tissue vs. plasma $\left(\mathrm{R}_{\mathrm{AUC} \_0-\infty}\right)$, where the latter three parameters reflect the permeability of levofloxacin in lung or bronchial mucosa. $\mathrm{T}_{\max }$ is the time when levofloxacin concentration reaches $\mathrm{C}_{\max }$. The area under the concentration-time curve $\mathrm{AUC}_{0-24}$ was calculated using the trapezoidal method: $\sum_{l=1}^{n} C_{i}+C_{i+1}\left(t_{i+1}-t_{i}\right) / 2$, where $C_{\mathrm{i}}$ and $t_{\mathrm{i}}$ indicate the concentration and time, respectively. The number of time-points (n) was 5 for plasma and 4 for lung tissue and bronchial mucosa. $T_{1 / 2}$ is calculated as $0.693 / \lambda$, where $\lambda$ is the terminal elimination rate. $\mathrm{MRT}_{0-24}$ was obtained as $\mathrm{AUMC} \mathrm{M-24} / \mathrm{AUC}_{0-24}$, where $\mathrm{AUMC}_{0-24}$ is the integration of $C \mathrm{x} t$ vs. time from 0 to $24 \mathrm{~h}$. The $\mathrm{CL}_{\mathrm{t}} / \mathrm{F}$ of levofloxacin is calculated as Dose/AUC $\mathrm{C}_{0-\infty}$, 
while the $\mathrm{V}_{\mathrm{d}} / \mathrm{F}$ is obtained as $\left(\mathrm{CL}_{\mathrm{t}} / \mathrm{F}\right) / \lambda$. Since there was no single time-concentration curve from 0 to $24 \mathrm{~h}$ from the same subject, the non-parametric bootstrap method was used to obtain the above parameters (23). Specifically, a new replication of the dataset (bootstrap sample) at each time-point was obtained using eight random draws of individual data (with replacement) from the original dataset. The non-compartment analysis was performed using average values of each new dataset and this process was repeated 200 times with different random draws. All the calculations were performed using Matlab software (version 7.0.1; Mathworks Inc.).

A pharmacokinetic model was developed to analyze the time profiles of levofloxacin in plasma, lung tissue and bronchial mucosa simultaneously (Fig. 1). The time profiles of the levofloxacin concentration in plasma and tissues were described using a one-compartment model. The elimination of levofloxacin from the central, lung and bronchial compartment, as well as the drug transport from the central to lung or bronchial compartment, were all consistent with first-order kinetics. The differential equations are as follows:

$$
\left\{\begin{array}{l}
\frac{d X_{a}}{d t}=-k_{a} \cdot X_{a} ; \quad X_{a, 0}=F \cdot \text { Dose } \\
\frac{d X_{1}}{d t}=k_{a} \cdot X_{a}-\frac{C L}{V_{1}} \cdot X_{1} ; \quad X_{1,0}=0 \\
\frac{d X_{2}}{d t}=f_{12} \cdot \frac{C L}{V_{1}} \cdot X_{1}-\frac{C L_{2}}{V_{2}} \cdot X_{2} ; \quad X_{2,0}=0 \\
\frac{d X_{3}}{d t}=f_{13} \cdot \frac{C L}{V_{1}} \cdot X_{1}-\frac{C L_{3}}{V_{3}} \cdot X_{3} ; X_{3,0}=0 \\
C_{1}=\frac{X_{1}}{V_{1}} ; C_{2}=\frac{X_{2}}{V_{2}} ; C_{3}=\frac{X_{3}}{V_{3}}
\end{array}\right.
$$

Where $X_{a}, X_{1}, X_{2}$ and $X_{3}$ are the amount of levofloxacin in absorption, central, lung and bronchial compartment, respectively, and $\mathrm{X}_{\mathrm{a}, 0}, \mathrm{X}_{1,0}, \mathrm{X}_{2,0}$ and $\mathrm{X}_{3,0}$ are the corresponding initial values. $k_{\mathrm{a}}$ and $F$ represent the absorption rate and bioavailability of levofloxacin. $C L$ and $V_{1}$ are the clearance of levofloxacin and distribution volume in the central compartment. $f_{12}$ and $f_{13}$ indicate the fraction of levofloxacin clearance from the lung and bronchial compartment, respectively. $\mathrm{CL}_{2}$ and $\mathrm{CL}_{3}$ are the clearance of levofloxacin from central to the lung and bronchial compartment. $\mathrm{V}_{2}$ is the weight of the lung, which was fixed as $1.2 \mathrm{~kg}$ according to previous literature (1/50 of the assumed body weight of $60 \mathrm{~kg})(24-26) . \mathrm{V}_{3}$ is the weight of the bronchial mucosa, which was fixed as a value of 1 , since the data were not identifiable. $\mathrm{C}_{1}, \mathrm{C}_{2}$ and $\mathrm{C}_{3}$ indicate the levofloxacin concentration in the plasma $(\mathrm{mg} / \mathrm{l})$, lung $(\mathrm{mg} / \mathrm{kg})$ and bronchial mucosa $(\mathrm{mg} / \mathrm{kg})$, respectively.

The PK model was developed in three steps: i) The mean $\mathrm{C}_{1}$ data were fit to obtain $\mathrm{CL}$, volume of distribution in central department $\left(\mathrm{V}_{1} / \mathrm{F}\right)$ and $k_{\mathrm{a}}$; ii) the mean $\mathrm{C}_{2}$ data were fit to obtain $f_{12}$ and $\mathrm{CL}_{2}$; iii) the mean $\mathrm{C}_{3}$ data were fit to obtain $f_{13}$ and $\mathrm{CL}_{3}$. Non-compartment analysis was used to provide initial estimates of the parameters. Model fittings were performed by non-linear regression analysis using a maximum likelihood algorithm in Matlab software. The ordinary differential equation functions were used to solve differential equations. Goodness of fit was evaluated by the objective function (mean residual fraction ratio) and by visual inspection of diagnostic plots. Non-parametric bootstrap analysis was performed

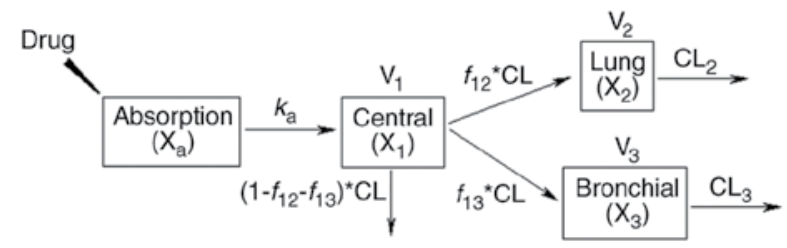

Figure 1. Pharmacokinetic model of levofloxacin in plasma, lung tissue and bronchial mucosa. $\mathrm{X}_{\mathrm{a}}, \mathrm{X}_{1}, \mathrm{X}_{2}$ and $\mathrm{X}_{3}$ denote the amount of levofloxacin in absorption, central, lung and bronchial compartment, respectively. $k_{\mathrm{a}}$ represents the absorption rate of levofloxacin. CL is the clearance of levofloxacin. $\mathrm{V}_{1}, \mathrm{~V}_{2}$, and $\mathrm{V}_{3}$ indicate the distribution volume in the central, lung, and bronchial compartment. $f_{12}$ and $f_{13}$ indicate the fraction of levofloxacin clearance from central to the lung and bronchial compartment, respectively. $\mathrm{CL}_{2}$ and $\mathrm{CL}_{3}$ are the clearance of levofloxacin from the lung and bronchial compartment, respectively.

in order to obtain more accurate parameter estimates. This process was similar to that in the non-compartment analysis. The stability of the final model was evaluated by inspection of the distribution of parameter estimates from the new datasets and comparing these with values obtained from the fit of the original dataset.

Statistical analysis. The demographic and baseline characteristics of patients were summarized and compared between groups. Values are expressed as $n$ or the mean \pm standard deviation. Continuous data were assessed using analysis of variance and the least-significant difference test. The categorical data, including sex, history of smoking and concomitant medications, were compared using Fisher's exact test. All statistical analyses were performed using SPSS software (version 19.0; IBM Corp.). $\mathrm{P}<0.05$ was considered to indicate a statistically significant difference.

$P K / P D$ analysis. Levofloxacin is a concentration-dependent quinolone antibiotic. The major $\mathrm{PK} / \mathrm{PD}$ parameters are AUC/MIC and $\mathrm{C}_{\max } / \mathrm{MIC}$ (26-28). The MIC data of levofloxacin were obtained from a previous study (29). The $f \mathrm{AUC}_{0-24} / \mathrm{MIC}_{90}$ and $f \mathrm{C}_{\max } / \mathrm{MIC}_{90}$ of levofloxacin were calculated using the PK parameters obtained from a non-compartment analysis, where $f$ is the free fraction of levofloxacin (0.7) (30). PK/PD analysis of levofloxacin was performed using Monte Carlo simulation. The simulated data of $\mathrm{AUC}_{0-24}$ and $\mathrm{C}_{\max }$ were obtained based on a logarithmic normal distribution. The simulated MIC values were generated based on a discrete distribution according to specified probability at each MIC level. The PK/PD targets of levofloxacin $\left(f \mathrm{AUC}_{0-24} / \mathrm{MIC} \geq 30 ; f \mathrm{C}_{\max } / \mathrm{MIC}\right.$ $\geq 5$ ) were used to predict the bacteriological efficacy of the drug against Streptococcus pneumonia (4,31-34). The probability of target attainment (PTA) of levofloxacin was calculated as the percentage of PK/PD parameter reaching the target at each specified MIC level, while the cumulative fraction of response (CFR) of levofloxacin was obtained as the percentage of PK/PD parameters attaining the target values (35). The simulation was performed in 5,000 patients using Matlab software.

\section{Results}

Baseline characteristics of patients. A total of 32 patients were enrolled in the present study. The underlying diseases of the 
Table III. Baseline characteristics of patients undergoing pulmonary operation (8 patients/group).

\begin{tabular}{lccccccc}
\hline Group & $\begin{array}{c}\text { Sex } \\
(\text { male/female) }\end{array}$ & $\begin{array}{c}\text { Age } \\
\text { (years) }\end{array}$ & $\begin{array}{c}\text { Body } \\
\text { weight }(\mathrm{kg})\end{array}$ & $\begin{array}{c}\mathrm{CL}_{\mathrm{cr}} \\
(\mathrm{ml} / \mathrm{min})\end{array}$ & $\begin{array}{c}\text { ALT } \\
(\mathrm{U} / \mathrm{l})\end{array}$ & $\begin{array}{c}\text { Smoking } \\
(\text { yes/no) }\end{array}$ & $\begin{array}{c}\text { Concomitant } \\
\text { drugs (yes/no) }\end{array}$ \\
\hline 1 & $7 / 1$ & $48 \pm 13$ & $65 \pm 10$ & $105 \pm 17$ & $23.9 \pm 13.8$ & $6 / 2$ & $0 / 8$ \\
2 & $6 / 2$ & $61 \pm 10$ & $64 \pm 7$ & $80 \pm 14$ & $18.8 \pm 7.21$ & $4 / 4$ & $0 / 8$ \\
3 & $3 / 5$ & $58 \pm 13$ & $65 \pm 10$ & $94 \pm 23$ & $22.3 \pm 8.43$ & $2 / 6$ & $2 / 6$ \\
4 & $4 / 4$ & $58 \pm 12$ & $61 \pm 12$ & $90 \pm 23$ & $21.6 \pm 14.8$ & $3 / 5$ \\
Total & $20 / 12$ & $56.0 \pm 12.0$ & $63.8 \pm 9.5$ & $92.2 \pm 20.9$ & $21.6 \pm 11.1$ & $14 / 18$ & $4 / 28$
\end{tabular}

Values are expressed as $\mathrm{n}$ or the mean \pm standard deviation. $\mathrm{CL}_{\mathrm{cr}}$, creatinine clearance calculated using Cockcroft-Gault formula; ALT, alanine aminotransferase.

Table IV. Concentration ratio of levofloxacin in patients undergoing pulmonary operation after oral administration of a single 500 -mg tablet ( $\mathrm{n}=8$ per group).

Concentration ratio ${ }^{\mathrm{a}}$

\begin{tabular}{lccc}
\cline { 2 - 3 } Group & Actual sampling time $(\mathrm{h})$ & Lung/plasma & Bronchial mucosa/plasma \\
\hline 1 & $4.5 \pm 0.2$ & $1.7 \pm 1.0^{\mathrm{b}}$ & $2.2 \pm 1.1^{\mathrm{b}}$ \\
2 & $7.3 \pm 1.3$ & $1.8 \pm 0.9^{\mathrm{b}}$ & $2.1 \pm 0.8^{\mathrm{b}}$ \\
3 & $11.6 \pm 0.8$ & $2.3 \pm 1.5^{\mathrm{c}}$ & $4.2 \pm 2.5^{\mathrm{a}, \mathrm{c}}$ \\
4 & $23.6 \pm 0.9$ & $3.8 \pm 2.0$ & $9.0 \pm 8.0$ \\
Overall & & $2.4 \pm 1.6$ & $4.4 \pm 5.0$
\end{tabular}

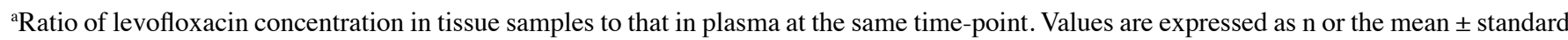
deviation. ${ }^{\mathrm{b}} \mathrm{P}<0.01$ and ${ }^{\mathrm{c}} \mathrm{P}<0.05$ compared with the corresponding ratio in group 4 .

patients included lung cancer $(n=23)$, old tuberculosis $(n=3)$, lung inflammatory granuloma $(n=3)$, right lung angioma $(n=1)$, chronic cavitation in the right lower lobe $(n=1)$ and bronchiectasis in the left lower lobe $(n=1)$. A total of $20(62.5 \%)$ male and $12(37.5 \%)$ female patients were enrolled, with an average age of $56 \pm 12$ (range 23-80) years and an average $\mathrm{CL}_{\mathrm{cr}}$ of $92.2 \pm 20.9 \mathrm{ml} / \mathrm{min}$. The baseline characteristics of sex, age, body weight, $\mathrm{CL}_{\mathrm{cr}}$ and alanine aminotransferase were well-balanced among the 4 patient groups ( $P>0.05$; Table III). No significant difference between history of smoking or use of concomitant drugs was present among the 4 groups.

Permeability of levofloxacin in lung tissue and bronchial mucosa. The mean concentration-time curves of levofloxacin in lung tissue, bronchial mucosa and plasma of the patients are presented in Fig. 1. Table IV presents the concentration ratio of levofloxacin in lung tissue and bronchial mucosa at each time-point. The $\mathrm{R}_{\mathrm{Cmax}}$ in lung tissue and bronchial mucosa was $1.7 \pm 1.0$ and $2.2 \pm 1.1$ at $4 \mathrm{~h}$ post-dose. These ratios increased to $3.8 \pm 2.0$ and $9.0 \pm 8.0$ at $24 \mathrm{~h}$, respectively. Statistical analysis demonstrated that the concentration ratio of levofloxacin at $24 \mathrm{~h}$ was significantly higher compared with that at other sampling times in lung tissue and bronchial mucosa (Table IV). The results also indicated that the mean concentration ratio of levofloxacin in bronchial mucosa was significantly higher compared with that in lung tissue at $24 \mathrm{~h}$ post-dose.
PK of levofloxacin. Non-compartment parameters of levofloxacin in plasma, lung tissue and bronchial mucosa are presented in Table V. For the majority of parameters, the values were ranked as plasma $<$ lung tissue $<$ bronchial mucosa. The $\mathrm{AUC}_{0-24}$ of levofloxacin in the plasma, lung tissue and bronchial mucosa was $65.2 \pm 4.0,85.7 \pm 8.5$ and $137.3 \pm 19.4 \mathrm{mg} \mathrm{h} / 1$, respectively. $\mathrm{R}_{\mathrm{AUC} \_0-24}$ was $1.3 \pm 0.2$ in the lung and $2.1 \pm 0.3$ in the bronchial mucosa. The levofloxacin concentration reached $\mathrm{C}_{\max }$ in plasma at $1.5 \mathrm{~h}$, while the concentration in lung tissue and bronchial mucosa reached $\mathrm{C}_{\max }$ at $4 \mathrm{~h}$ post-dose. The $\mathrm{C}_{\max }$ in lung tissue and bronchial mucosa was increased by 32 and $77 \%$ compared with that in plasma. The $\mathrm{T}_{1 / 2}$ of levofloxacin was increased by $46 \%$ in lung tissue and $254 \%$ in bronchial mucosa compared with that in plasma. The $\mathrm{MRT}_{0-24}$ of levofloxacin exhibited a similar pattern of change to that of $\mathrm{T}_{1 / 2}$.

The time profiles of levofloxacin in plasma, lung tissue and bronchial mucosa were well-described by the PK model (Fig. 2). The absorption rate of levofloxacin was $5.6 \mathrm{l} / \mathrm{h}$, while the $\mathrm{CL}_{\mathrm{t}} / \mathrm{F}$ was $7.8 \mathrm{l} / \mathrm{h}$ (Table VI). Bootstrapping for PK model showed that $f_{12}$ and $f_{13}$ were 0.128 and 0.074 , which indicate that the percentage sof the levofloxacin dose distributed to the lung and bronchial compartment was 12.8 and $7.4 \%$, respectively (Table VI). The parameter values obtained from the bootstrap dataset had almost the same order of magnitude as those from the original dataset. The coefficient of variation of parameters in tissue $\left(f_{12}, \mathrm{CL}_{2}, f_{13}\right.$ and $\left.\mathrm{CL}_{3}\right)$ obtained from the bootstrap 
Table V. Non-compartment parameters of levofloxacin following single oral administration of $500 \mathrm{mg}$ tablet in patients undergoing pulmonary operation.

\begin{tabular}{lrrr}
\hline Parameter & Plasma & Lung tissue & Bronchial mucosa \\
\hline $\mathrm{C}_{\max }(\mathrm{mg} / \mathrm{l}$ or $\mathrm{mg} / \mathrm{kg})$ & $5.4 \pm 0.7$ & $7.0 \pm 1.2$ & $9.4 \pm 2.1$ \\
$\mathrm{~T}_{\max }(\mathrm{h})$ & $1.7 \pm 0.9$ & $5.9 \pm 1.4$ & $6.4 \pm 2.8$ \\
$\mathrm{AUC}_{0-24}(\mathrm{mg} \mathrm{h} / \mathrm{l}$ or $\mathrm{mg} \mathrm{h} / \mathrm{kg})$ & $65.2 \pm 4.0$ & $85.7 \pm 8.5$ & $137.3 \pm 19.4$ \\
$\mathrm{AUC}_{0-\infty}(\mathrm{mg} \mathrm{h} / \mathrm{l}$ or $\mathrm{mg} \mathrm{h} / \mathrm{kg})$ & $69.4 \pm 4.1$ & $106.6 \pm 8.1$ & $273.7 \pm 129.7$ \\
$\mathrm{~T}_{1 / 2}(\mathrm{~h})$ & $6.1 \pm 0.7$ & $8.9 \pm 1.5$ & $21.6 \pm 14.2$ \\
$\mathrm{MRT}_{0-24}(\mathrm{~h})$ & $8.3 \pm 0.3$ & $9.9 \pm 0.4$ & $11.2 \pm 0.7$ \\
$\mathrm{CL}_{\mathrm{t}} / \mathrm{F}(\mathrm{l} / \mathrm{h})$ & $7.2 \pm 0.4$ & & \\
$\mathrm{~V}_{\mathrm{d}} / \mathrm{F}(\mathrm{l})$ & $63.7 \pm 8.1$ & & $1.3 \pm 0.3$ \\
$\mathrm{R}_{\mathrm{Cmax}}(\mathrm{l} / \mathrm{kg})$ & & $1.3 \pm 0.2$ & $2.1 \pm 0.3$ \\
$\mathrm{R}_{\mathrm{AUC} \_-24}(\mathrm{l} / \mathrm{kg})$ & & $1.5 \pm 0.1$ & $4.0 \pm 1.9$ \\
$\mathrm{R}_{\mathrm{AUC} \_-\infty}(\mathrm{l} / \mathrm{kg})$ & & & \\
\hline
\end{tabular}

Values are expressed as $\mathrm{n}$ or the mean \pm standard deviation. The results were obtained using a bootstrap method ( $\mathrm{n}=200)$. The units of $\mathrm{C}_{\max }$ and AUC in plasma were $\mathrm{mg} / \mathrm{l}$ and $\mathrm{mg} \mathrm{h} / \mathrm{l}$. As for lung tissue and bronchial mucosa, the units of $\mathrm{C}_{\max }$ and AUC were $\mathrm{mg} / \mathrm{kg}$ and $\mathrm{mg} \mathrm{h} / \mathrm{kg}$, respectively. $\mathrm{AUC}_{0-24}$, area under the concentration-time curve between 0 and $24 \mathrm{~h} ; \mathrm{C}_{\max }$, peak serum concentration; $\mathrm{T}_{\max }$, peak time; $\mathrm{T}_{1 / 2}$, half life; MRT, mean residence time; $\mathrm{CL}_{\mathrm{t}} / \mathrm{F}$, total apparent clearance; $\mathrm{V}_{\mathrm{d}} / \mathrm{F}$, apparent volume of distribution; $\mathrm{R}_{\mathrm{Cmax}}$, the ratio of $\mathrm{C}_{\max }$ in tissue vs. plasma.

dataset was relatively high (Table VI). This is consistent with the high standard deviation of the levofloxacin concentration in lung tissue and bronchial mucosa (Fig. 2).

Therapeutic implication of levofloxacin PK/PD. The PK/PD parameters of levofloxacin against common pathogens of community-acquired LRTIs are presented in Table VII. The $f \mathrm{AUC}_{0-24} / \mathrm{MIC}$ and $f \mathrm{C}_{\max } / \mathrm{MIC}$ of levofloxacin in lung tissue and bronchial mucosa were higher compared with those in plasma. The $f \mathrm{AUC}_{0-24} / \mathrm{MIC}$ was $45.6-182.5,60.0-239.8$ and 96.1-384.5 in plasma, lung tissue and bronchial mucosa, respectively, against gram-positive bacteria. The $f \mathrm{C}_{\max } / \mathrm{MIC}$ of levofloxacin was 3.8-15.1, 4.9-19.7 and 6.6-26.3 in the corresponding tissue. The PTA of PK/PD parameters of levofloxacin against $S$. pneumoniae are indicated in Fig. 3 . The PTA of levofloxacin $f \mathrm{AUC}_{0-24} / \mathrm{MIC}$ was maintained at $100 \%$ in plasma and lung tissue when $\mathrm{MIC} \leq 1 \mathrm{mg} / \mathrm{l}$. The PTA of $\mathrm{fAUC}_{0-24} / \mathrm{MIC}$ was $>90 \%$ in bronchial mucosa when the MIC was $\leq 2 \mathrm{mg} / \mathrm{l}$. The CFR of levofloxacin for S. pneumoniae was 90.6, 94.4 and $98.1 \%$ in plasma, lung tissue and bronchial mucosa, respectively, when $f \mathrm{AUC}_{0-24} / \mathrm{MIC}=30$. The $\mathrm{CFR}$ of levofloxacin $f \mathrm{C}_{\max } / \mathrm{MIC}$ was $44.7,64.8$ and $85.4 \%$ in the corresponding tissues.

\section{Discussion}

The results of the present study indicated that levofloxacin is able to rapidly penetrate into the lung tissue and bronchial mucosa. Following a single oral dose of $500 \mathrm{mg}$ levofloxacin, the average concentration of levofloxacin in plasma, lung tissue and bronchial mucosa was $3.6 \mu \mathrm{g} / \mathrm{ml}, 6.4$ and $8.7 \mu \mathrm{g} / \mathrm{g}$ at $4 \mathrm{~h}$ post-dose, and this was reduced to $0.5 \mu \mathrm{g} / \mathrm{ml}, 1.6$ and $4.1 \mu \mathrm{g} / \mathrm{g}$ at $24 \mathrm{~h}$. Compared with the plasma concentration, the levofloxacin concentration was higher in lung tissue and bronchial mucosa at 4-24 h post-dose. The average concentration ratio of the levofloxacin penetration into lung tissue was $2.4(0.7-7.8)$

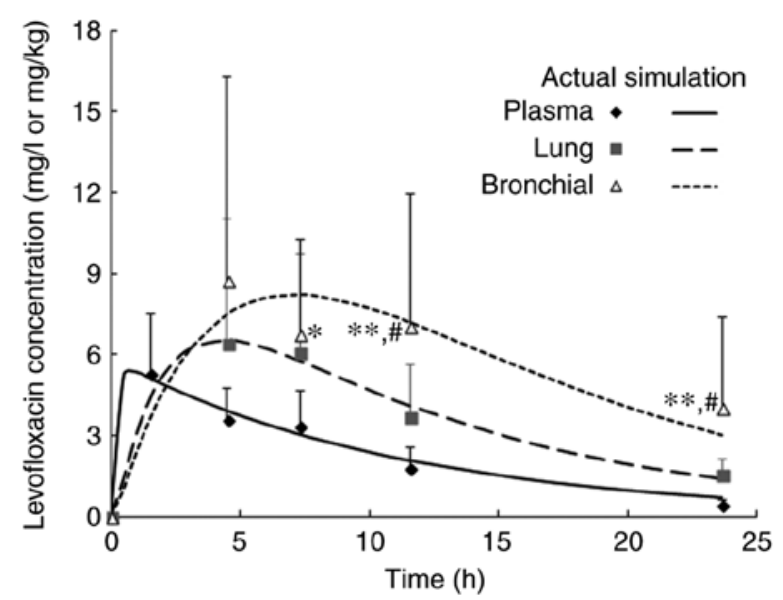

Figure 2. Time profiles of levofloxacin in plasma $(\mu \mathrm{g} / \mathrm{ml})$ or tissue samples $(\mu \mathrm{g} / \mathrm{g})$ after single oral administration of a 500-mg tablet in patients undergoing pulmonary operation. Values are expressed as the mean \pm standard deviation ( $\mathrm{n}=32$ at $1.5 \mathrm{~h}$ or 8 at the other time-points) and predictions were made by a pharmacokinetic model. ${ }^{*} \mathrm{P}<0.05,{ }^{* *} \mathrm{P}<0.01$ compared to plasma (least-significant difference test); ${ }^{\#} \mathrm{P}<0.05$ compared to lung tissue (least-significant difference test).

and the maximal concentration ratio value was observed at $24 \mathrm{~h}$ post-dose. The permeability of levofloxacin in lung tissue increased with time, demonstrating the high permeability of levofloxacin in lung tissue. Other studies have reported that the mean tissue permeability of levofloxacin was 4.0 within $24 \mathrm{~h}$ and 5.1 at $12 \mathrm{~h}$ following a single oral dose of $500 \mathrm{mg}$ levofloxacin in patients receiving pulmonary biopsy or pneumonectomy (36). These data are inconsistent with the results of the present study and may be due to the patients in the aforementioned studies being from different ethnic groups and exhibiting high inter-subject variability due to the smaller patient sample size. In the present study, a total of 8 Chinese patients were enrolled in each group. 
Table VI. Pharmacokinetic parameters of levofloxacin in patients undergoing pulmonary operation.

Bootstrap dataset

\begin{tabular}{lccr} 
Parameter (Unit) & Original dataset & Mean $\pm \mathrm{SD}^{\mathrm{a}}$ & $\mathrm{CV}(\%)$ \\
\hline$k_{\mathrm{a}}(\mathrm{l} / \mathrm{h})$ & 5.6 & $6.2 \pm 2.0$ & 32.6 \\
$\mathrm{CL}(\mathrm{l} / \mathrm{h})$ & 7.8 & $8.2 \pm 0.8$ & 9.8 \\
$\mathrm{~V}_{1} / \mathrm{F}(\mathrm{l})$ & 86.4 & $85.6 \pm 11.9$ & 13.9 \\
$f_{12}$ & 0.128 & $0.2 \pm 0.1$ & 77.7 \\
$\mathrm{CL}_{2}(\mathrm{l} / \mathrm{h})$ & 0.6 & $0.8 \pm 0.6$ & 72.3 \\
$f_{13}$ & 0.074 & $0.1 \pm 0.08$ & 69.3 \\
$\mathrm{CL}_{3}(\mathrm{l} / \mathrm{h})$ & 0.2 & $0.3 \pm 0.3$ & 75.9 \\
\hline
\end{tabular}

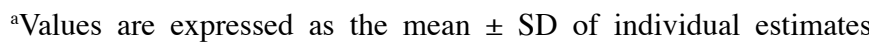
$(\mathrm{n}=200)$. SD, standard deviation; $\mathrm{CV}$, coefficient of variation; $f_{12}$, the fraction of levofloxacin clearance from central to the lung compartment; $f_{13}$, the fraction of levofloxacin clearance from central to the bronchial compartment; $k_{\mathrm{a}}$, absorption rate; CL, clearance rate from plasma; $\mathrm{CL}_{2}$, the clearance of levofloxacin from the lung compartment; $\mathrm{CL}_{3}$, the clearance of levofloxacin from the bronchial compartment; $\mathrm{V}_{1} / \mathrm{F}$, volume of distribution in central compartment.

Pulmonary lobectomy is an effective treatment for intrapulmonary and bronchial diseases (37). However, this procedure to remove the source of contamination in bronchi may cause infection (38), and is a critical occasion for the prophylactic use of antimicrobial agents. Following oral administration of a single dose of $500 \mathrm{mg}$ levofloxacin, the average concentration ratio of levofloxacin was 4.4 in bronchial mucosa within $24 \mathrm{~h}$, which was significantly higher compared with that in lung tissue (2.4). Compared with water-soluble drugs, lipid-soluble antimicrobial agents, including fluoroquinolones, are more readily absorbed through the cell membrane and exhibit increased tissue permeability (39). Antimicrobial agents have been extensively studied in sputum (40). However, sputum is non-homogeneous sample and may be easily diluted by saliva (41). Therefore, bronchial mucosa is more reliable than sputum in the evaluation of antimicrobial agent permeability in lung tissues (42); however, it is more difficult to collect samples of bronchial mucosa and lung tissue than sputum. The present study provided direct evidence for the tissue permeability of levofloxacin.

Zhang et al (2) indicated that the $\mathrm{C}_{\max } / \mathrm{MIC}_{90}$ ratio was 3-57 in epithelial lining fluid (ELF), and 1-6 in sputum following a single oral dose of $500 \mathrm{mg}$ levofloxacin at the fasting state in patients with LRTI undergoing bronchoalveolar lavage (2). The $\mathrm{AUC}_{0-24} \mathrm{~h} / \mathrm{MIC}_{90}$ of levofloxacin reached 35-138 and 9-38, respectively. Compared with the plasma concentration at the same time-point, the concentration ratio of levofloxacin in ELF was high ( 1.04 at $24 \mathrm{~h}$ after dosing), but the concentration ratio in sputum was low (0.09) (2). The results of the present study demonstrated that the permeability of levofloxacin is more prominent in lung tissue and bronchial mucosa following an oral dose of $500 \mathrm{mg}$, and is higher compared with that in ELF and sputum.
The $\mathrm{V}_{\mathrm{d}}$ of levofloxacin decreased significantly by $47.8 \%$ in patients undergoing pulmonary operation (1.0 vs. $1.9 \mathrm{l} / \mathrm{kg})$, $\mathrm{T}_{1 / 2}$ decreased by $34.8 \%$ (6.1 vs. $9.4 \mathrm{~h}$ ) and $\mathrm{C}_{\max }$ decreased by $23.1 \%$ (5.4 vs. $7.0 \mathrm{mg} / \mathrm{l}$ ), while the $\mathrm{AUC}_{0-24}$ and $\mathrm{AUC}_{0-\infty}$ of levofloxacin increased by $35.3 \%(65.2 \mathrm{mg} \mathrm{h} / 1 \mathrm{vs} .48 .2 \mathrm{mg} \mathrm{h} / \mathrm{l})$ and $26.7 \%$ (69.4 mg h/l vs. $54.8 \mathrm{mg} \mathrm{h} / 1$ ), respectively, compared with that in healthy subjects (43). These results indicated that a decreased distribution volume of levofloxacin may be the reason for the higher drug exposure in patients undergoing pulmonary operation.

During the development of the compartment model, the levofloxacin concentration data in plasma and lung tissue was fit using a two-compartment model, where the peripheral compartment represents lung tissue. The results indicated that the inter-compartment clearance of levofloxacin was close to zero. Subsequently, a model was developed where drug elimination from the peripheral compartment was introduced. Although the model fittings improved, the simulated concentration of levofloxacin in plasma was higher than the actual values at all time-points. A three-compartment model was also used to analyze the PK data of levofloxacin, where the two peripheral compartments represented lung tissue and bronchial mucosa and the simulation results were not satisfactory. The final PK model was obtained by simplification of this model and by introducing an elimination pathway from peripheral compartments (Fig. 1). For instance, the elimination of levofloxacin from the lung compartment represented the process of drug efflux from lung tissue to blood. The structure of the final PK model was similar to that of the PK model of moxifloxacin in patients with bronchopneumonia (44). The CL of levofloxacin was close to the non-compartment parameter $\mathrm{CL}_{\mathrm{t}} / \mathrm{F}$ and the distribution volume in the central compartment $\mathrm{V}_{1} / \mathrm{F}$ was similar to $\mathrm{V}_{\mathrm{d}} / \mathrm{F}$. The results of most PK parameters derived from the bootstrap method were close to the results calculated from original dataset, and this was supported by the standard deviation for PK parameters. This suggested that the estimation of the results of the final PK model were reliable.

The PK/PD parameters of levofloxacin determined in the present study were similar to the literature reports following the adjustment by dose and drug unbound fraction. For S.pneumoniae, the $\mathrm{C}_{\max } / \mathrm{MIC}_{90}$ and $\mathrm{AUC} / \mathrm{MIC}_{90}$ of levofloxacin in plasma were similar to those in patients with bronchitis or obstructive pulmonary disease (32). The results of the present study were also similar to a PK study of levofloxacin in elderly adults receiving diagnostic bronchoscopy (45). The $\mathrm{C}_{\max } / \mathrm{MIC}_{90}$ and $\mathrm{AUC} / \mathrm{MIC}_{90}$ of levofloxacin in lung tissue against $P$. aeruginosa and $K$. pneumoniae exhibited the same orders of magnitude to the parameter values in patients undergoing off-pump coronary artery bypass grafting (46).

The results indicated that the $f \mathrm{AUC}_{0-24} / \mathrm{MIC}_{90}$ of levofloxacin was only 3.7 in lung tissue against $P$. aeruginosa. This result indicated that levofloxacin cannot be recommended as a first-line therapy of LRTIs where P. aeruginosa is isolated or is suspected to be the causative pathogen. This result is similar to a PK/PD report of levofloxacin in acutely hospitalized elderly patients (27). A previous study demonstrated that a PK/PD model predicted that $500 \mathrm{mg}$ levofloxacin was not effective for treating multidrug- and drug-resistant tuberculosis (47-49). By contrast, the $f \mathrm{AUC}_{0-24} / \mathrm{MIC}$ of levofloxacin reached 60 in lung tissue against $S$. pneumoniae. The Monte Carlo simulation 
Table VII. Pharmacokinetic/pharmacodynamic parameters of levofloxacin in patients undergoing pulmonary operation following single oral administration of a 500-mg levofloxacin tablet.

\begin{tabular}{|c|c|c|c|c|c|c|c|}
\hline \multirow[b]{2}{*}{ Bacteria (no. of strains) } & \multirow[b]{2}{*}{$\mathrm{MIC}_{90}(\mathrm{mg} / \mathrm{l})$} & \multicolumn{3}{|c|}{$f \mathrm{AUC}_{0-24} / \mathrm{MIC}_{90}$} & \multicolumn{3}{|c|}{$f \mathrm{C}_{\max } / \mathrm{MIC}_{90}$} \\
\hline & & Plasma & Lung tissue & Bronchial mucosa & Plasma & Lung tissue & Bronchial mucosa \\
\hline $\operatorname{MSSA}(21)$ & 0.25 & 182.5 & 239.8 & 384.5 & 15.1 & 19.7 & 26.3 \\
\hline S. pneumoniae (28) & 1 & 45.6 & 60.0 & 96.1 & 3.8 & 4.9 & 6.6 \\
\hline H. influenzae (45) & 0.5 & 91.3 & 119.9 & 192.3 & 7.6 & 9.8 & 13.2 \\
\hline K. pneumoniae (87) & 1 & 45.6 & 60.0 & 96.1 & 3.8 & 4.9 & 6.6 \\
\hline P. aeruginosa (18) & 16 & 2.9 & 3.7 & 6.0 & 0.2 & 0.3 & 0.4 \\
\hline Acinetobacter spp. (22) & 0.25 & 182.5 & 239.8 & 384.5 & 15.1 & 19.7 & 26.3 \\
\hline
\end{tabular}

$\mathrm{MIC}_{90}$ was obtained from a previous study (29). $f$, unbound fraction of levofloxacin (0.7); MSSA, methicillin-susceptible $S$. aureus; MIC, minimum inhibitory concentration; $\mathrm{AUC}_{0-24}$, area under the concentration-time curve between 0 and $24 \mathrm{~h}$; $\mathrm{C}_{\max }$, peak serum concentration.

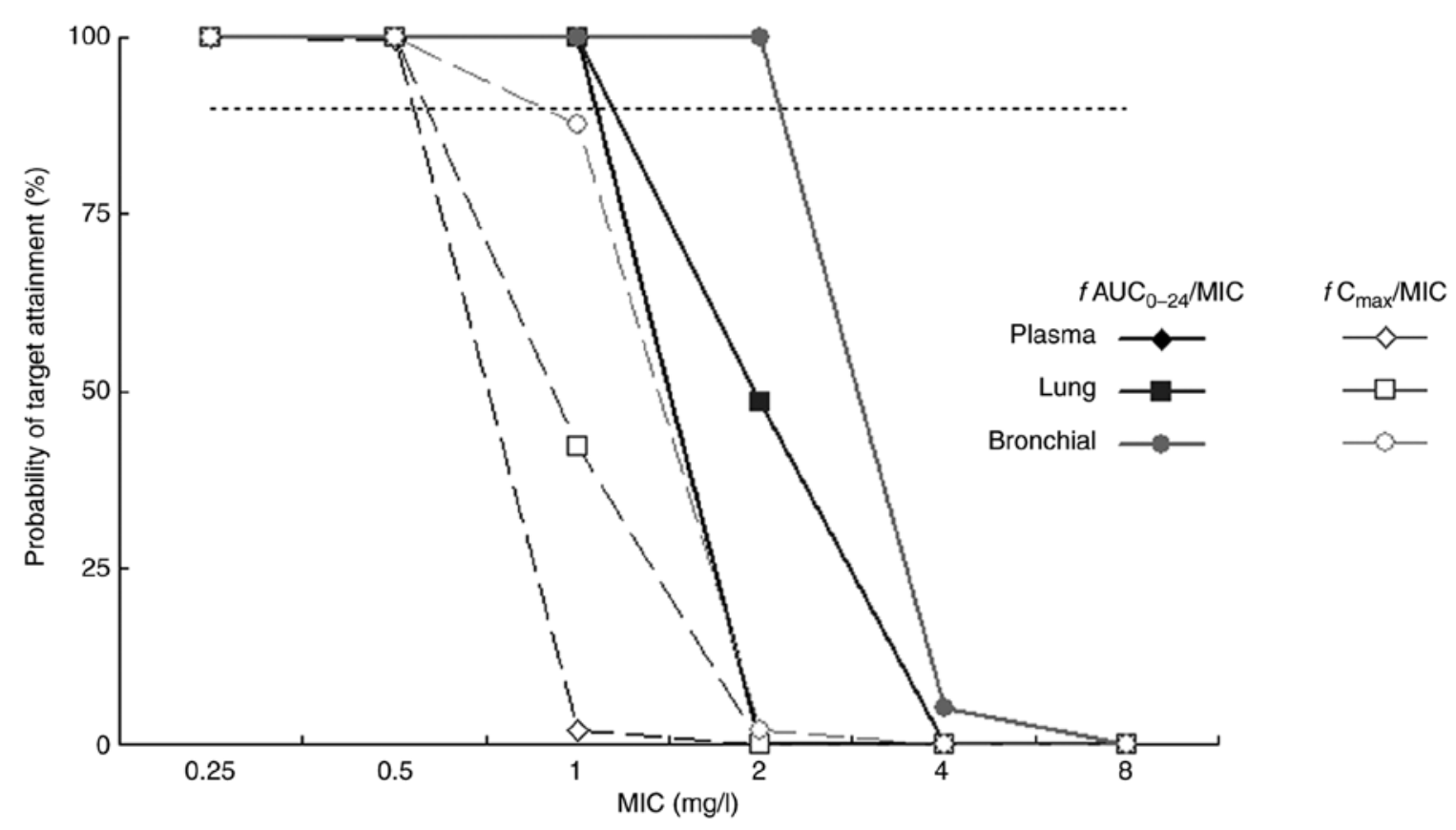

Figure 3. PTA of levofloxacin $f \mathrm{AUC}_{0-24} / \mathrm{MIC}$ (target=30) and $f \mathrm{C}_{\max } / \mathrm{MIC}$ (target=5) against $S$. pneumoniae in patients undergoing pulmonary operation following single oral administration of a 500-mg tablet. The horizontal line indicates the PTA value of $90 \%$ and $f$ is the unbound fraction of levofloxacin (0.7). MIC, minimal inhibitory concentration; AUC0-24, area under the concentration-time curve between 0 and $24 \mathrm{~h}$; $\mathrm{C}_{\max }$, peak serum concentration; PTA, probability target attainment.

revealed that the PTA of levofloxacin $f \mathrm{AUC}_{0-24} / \mathrm{MIC}$ in lung tissue and bronchial mucosa was maintained at $100 \%$ when $\mathrm{MIC} \leq 1 \mathrm{mg} / 1$ and the CFR of $f \mathrm{AUC}_{0-24} / \mathrm{MIC}$ was also $>90 \%$ in these two tissues. These results are supported by a population PK (PPK) study of levofloxacin (26), which indicated an $\mathrm{AUC}_{0-24}$ of $66.19 \pm 1.30 \mathrm{mg} \mathrm{h} / \mathrm{l}$ and the predicted CFR for a target $\mathrm{AUC}_{0-24} / \mathrm{MIC}$ ratio of 30 was $83.12 \%$ for $S$. aureus and $92.63 \%$ for $S$. pneumoniae. Due to the $\mathrm{MIC}_{90}$ of levofloxacin against $S$. pneumoniae being $1 \mathrm{mg} / \mathrm{l}$, it may be suggested that a levofloxacin $500 \mathrm{mg}$ dosing regimen has good clinical and microbiological efficacy in the treatment of pulmonary infections that are caused by S. pneumoniae.

In the present study, it was not possible to develop a PPK model of levofloxacin due to the small number of lung tissue and bronchial mucosa samples. It was impossible to estimate inter-subject variation due to there only being one data-point for each tissue sample type that was collected in one subject. Therefore, a compartment model was developed to analyze the PK data of levofloxacin in plasma, lung tissue and bronchial mucosa simultaneously. This provides more details about drug ADME compared with general non-compartment PK parameters. Treatment-emergent adverse events were not monitored, but the record of data did not indicate any significant or outstanding adverse events in the present study. The body mass index was also not calculated as patient height was not recorded. The standard error is particularly high for levofloxacin concentration in bronchial samples as compared with that in the 
other types of samples. This may be due to fewer number of samples at the time point of sampling and inter-individual variation. The bootstrap simulation in this study may offset this limitation to some extent.

To the best of our knowledge, the present study was the first to characterize the penetration of levofloxacin in bronchial mucosa. An integrated model was developed describing disposition and elimination of levofloxacin in plasma, lung tissue and bronchial mucosa, and PK/PD indices of levofloxacin in patients' bronchial mucosa were provided. The results indicated that levofloxacin is able to distribute to bronchi and lung tissues to reach an effective antimicrobial concentration after a single oral dose of $500 \mathrm{mg}$. The permeability of levofloxacin was demonstrated to be higher in bronchial mucosa compared with that in lung tissue. The PK/PD profiles of levofloxacin in lung tissues support the favorable efficacy of levofloxacin $500 \mathrm{mg}$ regimen for managing the community-acquired LRTIs that are caused by $S$. pneumoniae.

\section{Acknowledgements}

Not applicable.

\section{Funding}

The current study was supported by grants from the Ministry of Science and Technology of China (grant nos. 2012ZX09303004-001 and 2017ZX09304005) and the Natural Science Foundation of China (grant no. 81202582). Japan Daiichi Pharmaceutical Co. also sponsored this study.

\section{Availability of data and materials}

The datasets used and/or analyzed during the current study are available from the corresponding author on reasonable request.

\section{Authors' contributions}

GC, JZ and ZC conceived and designed the experiments, and wrote and modified the manuscript. YoZ and LP performed surgery and collected tissue samples. XX, YC and JY performed the PK/PD analysis. YiZ, JZ and YS critically interpreted the data and reviewed the manuscript. All authors read and approved the final manuscript.

\section{Ethics approval and consent to participate}

All study procedures in this study were approved by the Ethics Committee of Huashan Hospital, Fudan University (Shanghai, China). All patients provided written informed consent form prior to participation in the study.

\section{Patient consent for publication}

Not applicable.

\section{Competing interests}

The authors declare that they have no competing interests.

\section{References}

1. Torres A and Liapikou A: Levofloxacin for the treatment of respiratory tract infections. Expert Opin Pharmacother 13: 1203-1212, 2012.

2. Zhang J, Xie X, Zhou X, Chen YQ, Yu JC, Cao GY, Wu XJ, Shi YG and Zhang YY: Permeability and concentration of levofloxacin in epithelial lining fluid in patients with lower respiratory tract infections. J Clin Pharmacol 50: 922-928, 2010.

3. Nakajima T, Kaji Y and Miyawaki M: Penetration of single-dose levofloxacin into intestinal tissue. J Gastroen Hepatol Res 2: 399-402, 2013

4. Hutschala D, Skhirtladze K, Zuckermann A, Wisser W, Jaksch P, Mayer-Helm BX, Burgmann H, Wolner E, Müller M and Tschernko EM: In vivo measurement of levofloxacin penetration into lung tissue after cardiac surgery. Antimicrob Agents Chemother 49: 5107-5111, 2005.

5. Grossman RF, Rotschafer JC and Tan JS: Antimicrobial treatment of lower respiratory tract infections in the hospital setting. Am J Med 118 (Suppl): 29S-38S, 2005.

6. Andes D and Craig WA: Animal model pharmacokinetics and pharmacodynamics: A critical review. Int J Antimicrob Agents 19: 261-268, 2002.

7. Friedman H, Song X, Crespi S and Navaratnam P: Comparative analysis of length of stay, total costs, and treatment success between intravenous moxifloxacin $400 \mathrm{mg}$ and levofloxacin $750 \mathrm{mg}$ among hospitalized patients with community-acquired pneumonia. Value Health 12: 1135-1143, 2009.

8. Frei CR, Jaso TC, Mortensen EM, Restrepo MI, Raut MK, Oramasionwu CU, Ruiz AD, Makos BR, Ruiz JL, Attridge RT, et al: Medical resource utilization among community-acquired pneumonia patients initially treated with levofloxacin $750 \mathrm{mg}$ daily versus ceftriaxone $1000 \mathrm{mg}$ plus azithromycin $500 \mathrm{mg}$ daily: A US-based study. Curr Med Res Opin 25: 859-868, 2009

9. Schein J, Janagap-Benson C, Grant R, Sikirica V, Doshi D and Olson W: A comparison of levofloxacin and moxifloxacin use in hospitalized community-acquired pneumonia (CAP) patients in the US: Focus on length of stay. Curr Med Res Opin 24: 895-906, 2008.

10. Lynch JP III, File TM Jr and Zhanel GG: Levofloxacin for the treatment of community-acquired pneumonia. Expert Rev Anti Infect Ther 4: 725-742, 2006.

11. DiPiro JT: Short-term prophylaxis in clean-contaminated surgery. J Chemother 11: 551-555, 1999.

12. Radu DM, Jauréguy F, Seguin A, Foulon C, Destable MD, Azorin $\mathrm{J}$ and Martinod E: Postoperative pneumonia after major pulmonary resections: An unsolved problem in thoracic surgery. Ann Thorac Surg 84: 1669-1673, 2007.

13. Schussler O, Alifano M, Dermine H, Strano S, Casetta A, Sepulveda S, Chafik A, Coignard S, Rabbat A and Regnard JF: Postoperative pneumonia after major lung resection. Am J Respir Crit Care Med 173: 1161-1169, 2006.

14. Belda J, Cavalcanti M, Ferrer M, Serra M, Puig de la Bellacasa J, Canalis E and Torres A: Bronchial colonization and postoperative respiratory infections in patients undergoing lung cancer surgery. Chest 128: 1571-1579, 2005.

15. Bratzler DW and Houck PM: Antimicrobial prophylaxis for surgery: An advisory statement from the National Surgical infection prevention project. Am J Surg 189: 395-404, 2005.

16. Gupta R, Sinnett D, Carpenter R, Preece PE and Royle GT: Antibiotic prophylaxis for post-operative wound infection in clean elective breast surgery. Eur J Surg Oncol 26: 363-366, 2000.

17. Bratzler DW, Houck PM, Richards C, Steele L, Dellinger EP, Fry DE, Wright C, Ma A, Carr K and Red L: Use of antimicrobial prophylaxis for major surgery: Baseline results from the National Surgical Infection Prevention Project. Arch Surg 140: 174-182, 2005.

18. Malone DL, Genuit T, Tracy JK, Gannon C and Napolitano LM: Surgical site infections: Reanalysis of risk factors. J Surg Res 103: 89-95, 2002.

19. Von Baum H, Böttcher S, Hoffmann H and Sonntag HG: Tissue penetration of a single dose of levofloxacin intravenously for antibiotic prophylaxis in lung surgery. $\mathrm{J}$ Antimicrob Chemother 47: 729-730, 2001.

20. Swoboda S, Oberdorfer K, Klee F, Hoppe-Tichy T, von Baum H and Geiss HK: Tissue and serum concentrations of levofloxacin $500 \mathrm{mg}$ administered intravenously or orally for antibiotic prophylaxis in biliary surgery. J Antimicrob Chemother 51: $459-462,2003$ 
21. Cockcroft DW and Gault MH: Prediction of creatinine clearance from serum creatinine. Nephron 16: 31-41, 1976.

22. Xie X, Zhang J, Yu JC. Shi YG and Zhang YY: HPLC assay of levofloxacin concentration in plasma, lung tissue, and body fluids. Chin J Clin Pharmacol Ther 17: 158-162, 2008.

23. Chen Y, Cao Y, Zhou J and Liu X: Mechanism-based pharmacokinetic-pharmacodynamic modeling of bidirectional effect of danshensu on plasma homocysteine in rats. Pharm Res 26 : $1863-1673,2009$.

24. Askenazi SS and Perlman M: Pulmonary hypoplasia: Lung weight and radial alveolar count as criteria of diagnosis. Arch Dis Child 54: 614-618, 1979.

25. Qi XL, Bo AH and Xia L: Determination of cerebral and lung weight of fetus. Chin J Birth Health Heredity 65: 65, 1993.

26. Jaruratanasirikul S, Jaspattananon A, Wongpoowarak W, Nawakitrangsan M, Thengyai S and Samaeng M: Population pharmacokinetics and pharmacodynamics modeling of oral levofloxacin. J Med Assoc Thai 99: 886-892, 2018.

27. Cojutti PG, Ramos-Martin V, Schiavon I, Rossi P, Baraldo M, Hope W and Pea F: Population pharmacokinetics and pharmacodynamics of levofloxacin in acutely hospitalized older patients with various degrees of renal function. Antimicrob Agents Chemothe 61: e02134-16. 2017.

28. Scaglione F, Mouton JW, Mattina R and Fraschini F: Pharmacodynamics of levofloxacin and ciprofloxacin in a murine pneumonia model: Peak concentration/MIC versus area under the curve/MIC ratios. Antimicrob Agents Chemother 47: 2749-2755. 2003.

29. Zhang YY, Huang HH and Ren ZY: Clinical evaluation of oral levofloxacin $500 \mathrm{mg}$ once-daily dosage for treatment of lower respiratory tract infections and urinary tract infections: A prospective multicenter study in China. J Infect Chemother 15: 301-311, 2009.

30. Cao G, Zhang J, Wu X, Yu J, Chen Y, Ye X, Zhu D, Zhang Y, Guo B and Shi Y: Pharmacokinetics and pharmacodynamics of levofloxacin injection in healthy Chinese volunteers and dosing regimen optimization. J Clin Pharm Ther 38: 394-400, 2013.

31. Rodvold KA, Danziger LH and Gotfried MH: Steady-state plasma and bronchopulmonary concentrations of intravenous levofloxacin and Azithromycin in healthy adults. Antimicrob Agents Chemother 47: 2450-2457, 2003.

32. Conte JE Jr, Golden JA, McIver M, Little E and Zurlinden E: Intrapulmonary pharmacodynamics of high-dose levofloxacin in subjects with chronic bronchitis or chronic obstructive pulmonary disease. Int J Antimicrob Agents 30: 422-427, 2007.

33. Preston SL, Drusano GL, Berman AL, Fowler CL, Chow AT, Dornseif B, Reichl V, Natarajan J and Corrado M: Pharmacodynamics of levofloxacin: A new paradigm for early clinical trials. JAMA 279: 125-129, 1998

34. Zhang J, Yu JC, Shi YG, Zhou L, Ye XY, Zhu DM and Zhang YY: Study of pharmacokinetics/pharmacodynamics of levofloxacin. Zhonghua Yi Xue Za Zhi 85: 1926-1932, 2005 (In Chinese).

35. Wu XJ, Zhang J, Guo BN, Zhang YY, Yu JC, Cao GY, Chen YC Zhu DM, Ye XY, Wu JF, et al: Pharmacokinetics and pharmacodynamics of multiple-dose intravenous nemonoxacin in healthy Chinese volunteers. Antimicrob Agents Chemother 59: 1446-1454, 2015.
36. Lee LJ, Sha X, Gotfried MH, Howard JR, Dix RK and Fish DN: Penetration of levofloxacin into lung tissue after oral administration to subjects undergoing lung biopsy or lobectomy. Pharmacotherapy 18: 35-41, 1998.

37. Wang CQ, Wang W, Jin MH, Huang Q and Guan Q: Pulmonary resections in surgical treatment of lung tuberculosis. J Clin Pulmonary Med 14: 906-908, 2009.

38. Li P, Mao YB and Liu CT: Risk factors for surgical site infections in patients undergoing pneumonectomy. Chin J Nosocomiol 23: 5198-5199-5202, 2013.

39. Pea F: Intracellular pharmacokinetics of antibacterials and their clinical implications. Clin Pharmacokinet 57: 177-189, 2018

40. Moriarty TF, McElnay JC, Elborn JS and Tunney MM: Sputum antibiotic concentrations: Implications for treatment of cystic fibrosis lung infection. Pediatr Pulmonol 42: 1008-1017, 2007.

41. Kelly MM, Efthimiadis A and Hargreave FE: Induced sputum: Selection method. Methods Mol Med 56: 77-91, 2001.

42. Cazzola M, Blasi F, Terzano C, Matera MG and Marsico SA: Delivering antibacterials to the lungs: Considerations for optimizing outcomes. Am J Respir Med 1: 261-272, 2002.

43. Yu JC, Zhang J and Cao GY: Single-dose and multiple-dose pharmacokinetics of levofloxacin in Chinese healthy subjects. J Third Mil Med Univ 35: 2516-2520, 2013.

44. Simon N, Sampol E, Albanese J, Martin C, Arvis P, Urien S, Lacarelle B and Bruguerolle B: Population pharmacokinetics of moxifloxacin in plasma and bronchial secretions in patients with severe bronchopneumonia. Clin Pharmacol Ther 74: 353-363, 2003.

45. Capitano B, Mattoes HM, Shore E, O'Brien A, Braman S, Sutherland C and Nicolau DP: Steady-state intrapulmonary concentrations of moxifloxacin, levofloxacin, and azithromycin in older adults. Chest 125: 965-973, 2004.

46. Hutschala D, Kinstner C, Skhirtladze K, Mayer-Helm BX, Zeitlinger M, Wisser W, Müller M and Tschernko E: The impact of perioperative atelectasis on antibiotic penetration into lung tissue: An in vivo microdialysis study. Intensive Care Med 34: $1827-1834,2008$

47. Van't Boveneind-Vrubleuskaya N, Seuruk T, van Hateren K, van der Laan T, Kosterink JGW, van der WerfTS, van Soolingen D, van den Hof S, Skrahina A and Alffenaar JC: Pharmacokinetics of levofloxacin in multidrug- and extensively drug-resistant tuberculosis patients. Antimicrob Agents Chemother 61: pii: e00343-17. 2017.

48. Al-Shaer MH, Alghamdi WA, Alsultan A, An G, Ahmed S, Alkabab Y, Banu S, Barbakadze K, Houpt E, Kipiani M, et al: Fluoroquinolones in drug-resistant tuberculosis: Culture conversion and pharmacokinetic/pharmacodynamic target attainment to guide dose selection. Antimicrob Agents Chemother 63: pii: e00279-19, 2019.

49. U.S. Department of Health and Human Services. FDA guidance for industry: Population Pharmacokinetics, July 2019. https://www.fda.gov/media/128793/download. Accessed October 2019. 